\title{
Pattern of Drug Information Queries in a South Indian Tertiary Care Teaching Hospital
}

\author{
H. R. BRIGHT* AND J. V. PETER
}

Pharmacy Services, Christian Medical College, Vellore-632 004, India

\section{Bright et al.: Drug Information Queries}

Drug information centers have been established to provide unbiased information to healthcare workers and patients. The pattern of drug information queries received and answered by the drug information centre in a tertiary care teaching hospital in South India was assessed. Prospectively documented drug information queries, received and answered by the drug information centre over a 15-month period, were reviewed retrospectively for various parameters including status of the requestor, mode of receipt, mode of reply, type of query, purpose of query and references used. A total of 2010 queries were received and answered during the study period. Queries were received mainly from physicians (41 \%), followed by nurses (n=595; $30 \%)$ and pharmacists $(n=462 ; 23 \%)$. Dentists, students and healthcare professionals from outside the institution accounted for 139 (6 \%) queries. Internet-based resource was the main reference source $(n=952 ; 47 \%)$ followed by textbooks, intranet resources and journals. Patient care-related queries were the most common. The information sought included product identification $(22 \%)$, drug dose or schedule (16\%), product availability (13\%), drug of choice/therapeutic alternatives/therapeutic use (10\%), product information (10\%), drug use in special populations and administration (6\% each), compatibility/stability/storage $(5 \%)$ and adverse reactions $(4 \%)$. The drug information centre in a teaching hospital handles a wide range of queries from various healthcare workers, meets specific healthcare needs and serves as a valuable source of drug information. The impact of this service on improving patient care and minimizing errors warrants further study.

Key words: Drug information centre, drug information services, query, pattern 
Between 1900 and 1960, the number of available drugs and journal articles expanded. It became more and more difficult for physicians to keep abreast of medical literature. Thus the need arose for medical information retrieval. This led to the opening of the first drug information centre at the University of Kentucky in 1962. During the 1980s, the number of pharmacistoperated drug information centers peaked in the US; however since 1986, formal drug information centers began to close down due to lack of budget ${ }^{[1]}$. It was then, the drug information centers broadened their scope with more sophisticated activities that included educating allied health-profession students, providing evidence-based medical information, drug consultation, supporting the institutions' medication safety programme and providing information systems support $^{[2]}$.

Today, the scope of this service has expanded with the internet providing abundant information on medications to healthcare professionals and patients. As more information becomes available, greater attention needs to be paid not only to the content but also to up-to-date, unbiased drug information ${ }^{[3]}$. Since biases can creep in due to access to drug samples ${ }^{[4]}$ and pharmaceutical industry-sponsored clinical trials ${ }^{[5]}$, it is imperative to provide independent, unbiased drug information.

In the hospital setting, drug information centers and drug bulletins are two ways of disseminating information on medications. The presence of a drug information centre with a dedicated pharmacist, who provides drug information and formulary management, has been shown to be associated with significant reduction in cost and fewer deaths ${ }^{[6]}$. Disappointingly, an online survey of healthcare professionals showed that only $1 \%$ of respondents contact the drug information centre when the need arises ${ }^{[7]}$. In addition, in another study that compared the information obtained from Usenet newsgroup with drug information centers, responses were more accurate $(\mathrm{p}=0.001)$ from the drug information centre than from a Usenet newsgroup ${ }^{[8]}$.

This retrospective study was thus undertaken to explore the pattern of drug information queries received by the drug information centre in a South Indian tertiary care teaching hospital, to find out the common unmet drug information needs of the beneficiaries as well as identify beneficiaries of this service. The information obtained would help to improve the quality of service in a focused way.

The study was conducted in the drug information centre of a 2700-bedded tertiary care teaching hospital in South India. The study was approved by the Institutional Review Board (8909 [RETRO] dated 23.04.2014). The drug information centre, named DISH (Drug Information Services for Hospital) was established in 1984 and is an integral part of pharmacy services. It is well-equipped with qualified pharmacists trained in handling drug information queries, a library with adequate number of standard drug information textbooks, national and international medical and pharmaceutical journals and access to licensed drug information websites, internet and intranet facilities, computers and telephone. The service is provided only during regular working hours. The drug information service can be accessed through telephone, by visiting the centre in person, during ward rounds by clinical pharmacists, by e-mail or through a referral system. The responses to queries are provided in a manner convenient to the requestor either immediately or in accordance with the need of the requestor. All queries are documented in a dedicated file.

Documented drug information queries received and answered by DISH over 15-mo ( $1^{\text {st }}$ January 2013 to $31^{\text {st }}$ March 2014) were reviewed retrospectively. All queries answered were included in the study. Queries received but not answered because of unavailability of the requestor or wrong contact numbers were excluded. The parameters reviewed included status of the requestor, mode of receipt, mode of reply, type of query, purpose of query and references used. The status of the requestor was categorised into 8 groups that included physicians, nurses, pharmacists, dentists, students, other healthcare professionals, patients and healthcare professionals from outside the institution. The mode of receipt and reply were categorised as telephone, in person, ward round, referral system, e-mail, and written information. The purpose of the query was divided into patient care, self-education,

This is an open access article distributed under the terms of the Creative Commons Attribution-NonCommercial-ShareAlike 3.0 License, which allows others to remix, tweak, and build upon the work non-commercially, as long as the author is credited and the new creations are licensed under the identical terms

Accepted 05 August 2018

Revised 28 January 2018

Received 09 June 2017

${ }^{*}$ Address for correspondence

E-mail: heberrewbright@hotmail.com

966

Indian Journal of Pharmaceutical Sciences
Indian J Pharm Sci 2018;80(5):965-970 
research, and other purposes. References were divided broadly as internet/search engines, textbooks, intranet, journals and others. The type of query was classified into 30 based on the drug consultation request form published in a standard guide on drug information for pharmacists ${ }^{[9]}$. Retrieved data were entered into Microsoft Excel spreadsheet, collated and analysed for parameter outcomes. Descriptive statistics were analysed by calculating percentage values of each outcome parameter.

A total of 2010 queries were answered during the study period. This corresponded to 134 queries per month. Among these, physicians formed the major group with $814(41 \%)$ queries, followed by nurses $(n=595 ; 30 \%)$ and pharmacists $(\mathrm{n}=462 ; 23 \%)$. Other healthcare professionals that included students, dentists and healthcare professionals from outside the institution together accounted for 139 (6\%) queries. Most of the queries $(92 \%)$ were received via telephone; 126 queries $(6 \%)$ were received during ward rounds, $18(1 \%)$ directly in person and $11(1 \%)$ were referred queries. In reply, 1851 (92\%) queries were answered via telephone as most of the requestors felt convenient with this mode. 141 (7\%) queries were answered directly in person, $9(0.5 \%)$ each were answered by e-mail and printed materials.

Patient care related queries were the most common $(n=1748 ; 87 \%)$, followed by self-education $(n=167$; $8 \%)$, research purpose $(\mathrm{n}=13 ; 1 \%)$ and other purposes $(\mathrm{n}=82 ; 4 \%)$ that included information for third parties, drug purchase, formulary committee. Although, specific references used were documented, a comprehensive analysis of common references used was not explored in this study. Instead references were broadly classified and analysed. Internet/search engines were the choice of reference for a majority of the queries $(n=952$; $47 \%$ ), followed by standard drug information textbooks $(\mathrm{n}=637 ; 32 \%)$, intranet $(\mathrm{n}=436 ; 22 \%)$ and primary medical journals $(\mathrm{n}=56 ; 3 \%)$. Other references were used 170 times $(8 \%)$. The intranet was used mainly to answer questions related to product availability and product information while primary medical journals were used when comprehensive answers were sought by requestors. The complete demographics of the study are given in Table 1.

Product identification $(n=437 ; 22 \%)$ was the frequent drug information need of requestors. Dose/schedule was the second common unmet drug information need with 326 (16\%) queries, followed by product
TABLE 1: DEMOGRAPHICS OF THE STUDY

\begin{tabular}{|c|c|c|c|}
\hline \multicolumn{4}{|c|}{ Demographics of the study $(n=2010)$} \\
\hline S. No. & Characteristics & Number & Percentage \\
\hline \multicolumn{4}{|c|}{ Professional status of requestor } \\
\hline 1 & Physicians & 814 & 41 \\
\hline 2 & Nurses & 595 & 30 \\
\hline 3 & Pharmacists & 462 & 23 \\
\hline 4 & $\begin{array}{l}\text { Other healthcare } \\
\text { professionals }\end{array}$ & 69 & 3 \\
\hline 5 & $\begin{array}{l}\text { Healthcare professionals } \\
\text { from outside CMC }\end{array}$ & 21 & 1 \\
\hline 6 & Students & 39 & 2 \\
\hline 7 & Dentists & 6 & $<1$ \\
\hline 8 & Patients & 4 & $<1$ \\
\hline \multicolumn{4}{|c|}{ Mode of receipt } \\
\hline 1 & Phone & 1855 & 92 \\
\hline 2 & In person & 18 & 1 \\
\hline 3 & Ward round & 126 & 6 \\
\hline 4 & Referred by & 11 & 1 \\
\hline \multicolumn{4}{|c|}{ Mode of reply } \\
\hline 1 & Phone & 1851 & 92 \\
\hline 2 & In person & 141 & 7 \\
\hline 3 & E-mail & 9 & 0.5 \\
\hline 4 & Written Information & 9 & 0.5 \\
\hline \multicolumn{4}{|c|}{ Purpose of query } \\
\hline 1 & Patient care & 1748 & 87 \\
\hline 2 & Self-education & 167 & 8 \\
\hline 3 & Research & 13 & 1 \\
\hline 4 & Others* & 82 & 4 \\
\hline \multicolumn{4}{|c|}{ References } \\
\hline 1 & Internet/search engine & 952 & 47 \\
\hline 2 & Textbooks & 637 & 32 \\
\hline 3 & Intranet & 436 & 22 \\
\hline 4 & Journals & 56 & 3 \\
\hline 5 & Others $^{\dagger}$ & 170 & 8 \\
\hline
\end{tabular}

*Others included information for third parties including relatives, for drug purchase, formulary committee; †Others included expert opinions, information obtained from concerned departments, manufacturers

availability/status ( $\mathrm{n}=254 ; 13 \%)$, drug of choice/ therapeutic alternatives/therapeutic use $(n=206 ; 10 \%)$, product information $(195 ; 10 \%)$, drug use in special populations $(\mathrm{n}=129 ; 6 \%)$, method of administration (111; $6 \%)$, compatibility/stability/storage $(n=95 ; 5 \%)$, adverse drug reaction (ADR)/intolerance $(\mathrm{n}=72 ; 4 \%)$, drug interactions $(\mathrm{n}=59 ; 3 \%)$. The other query types are shown in Table 2.

The ongoing assessment of pattern of drug information queries is essential to improve the quality of a drug information centre. In this large study $(n=2010)$ of drug information queries over a 15-mo period, patient care related queries formed the bulk of queries. It was interesting to note that apart from the common drug information queries reported in similar studies ${ }^{[10]}$, the 
centre also received queries on a spectrum of issues ranging from legal matters, alternative medicine, poisoning and medical devices. These observations showcase the value of such a centre and highlight the role played by a properly established and run drug information centre.

In the current study, physicians were the primary users of this service $(41 \%)$ followed by nurses and pharmacists. This finding is consistent with other drug information centers in the US, Uganda and Nepal[11] where physicians constituted $50,54.2$ and $74.5 \%$ of the queries, respectively. However the proportion of $41 \%$ is less than other studies, probably due to several other healthcare professionals accessing our service. As with other studies, nurses were the next highest users followed by pharmacists. Although the number of queries from dentists was small $(<1 \%)$, other studies have not reported queries from this group. The total number of queries received per month in our centre of 134 was much higher than those reported (28, 27 and 9, respectively) from earlier studies ${ }^{[1-13]}$. The high utilization of this service may be due to three factors- the size of the institution, location (developing country) and the timing of the study (recent). Underutilization of drug information services by healthcare professionals and students may be attributed to unawareness of the service. Awareness could possibly be increased by campaigns among potential beneficiaries; however the impact of this is unclear ${ }^{[14]}$.

The most frequent queries related to product identification and availability, drug dose, drug use in special populations, drug administration and

TABLE 2: DISTRIBUTION OF TYPE OF QUERIES AMONG REQUESTORS

\begin{tabular}{|c|c|c|c|c|c|c|c|c|c|c|}
\hline Type of query & $\begin{array}{l}\frac{\pi}{0} \\
\frac{\pi}{n} \\
\frac{c}{a}\end{array}$ & $\begin{array}{l}\stackrel{\Xi}{5} \\
\bar{z}\end{array}$ & $\begin{array}{l}\frac{\hbar}{0} \\
\frac{\pi}{E} \\
\frac{E}{\sigma} \\
\frac{c}{\alpha} \\
\end{array}$ & 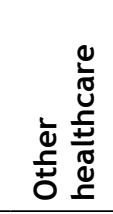 & 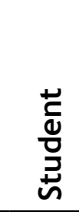 & 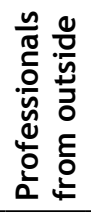 & 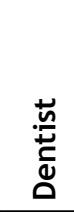 & 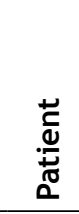 & $\begin{array}{l}\bar{\pi} \\
\stackrel{+}{0} \\
\stackrel{0}{*}\end{array}$ & 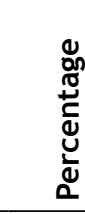 \\
\hline Product identification & 151 & 147 & 111 & 13 & 13 & 2 & - & - & 437 & $22 \%$ \\
\hline Dose/schedule & 189 & 27 & 104 & 1 & 2 & 2 & 1 & - & 326 & $16 \%$ \\
\hline Product availability/status & 140 & 34 & 46 & 12 & 4 & 12 & 4 & 2 & 254 & $13 \%$ \\
\hline $\begin{array}{l}\text { Drug of choice/therapeutic alternatives/therapeutic } \\
\text { use }\end{array}$ & 57 & 100 & 34 & 8 & 5 & 1 & - & 1 & 206 & $10 \%$ \\
\hline Product information & 52 & 90 & 34 & 8 & 9 & 2 & - & - & 195 & $10 \%$ \\
\hline Drug use in special populations & 81 & 7 & 36 & 3 & - & 2 & - & - & 129 & $6 \%$ \\
\hline Administration & 29 & 59 & 19 & 3 & - & - & - & 1 & 111 & $6 \%$ \\
\hline Compatibility/stability/storage & 18 & 62 & 14 & 1 & - & - & - & - & 95 & $5 \%$ \\
\hline ADR/intolerance & 48 & 7 & 13 & 3 & - & - & 1 & - & 72 & $4 \%$ \\
\hline Excipients/compounding/formulations & 14 & 8 & 41 & 1 & - & - & - & - & 64 & $3 \%$ \\
\hline Drug interactions & 54 & & 4 & 1 & & & & & 59 & $3 \%$ \\
\hline Cost/pharmacoeconomics & 25 & 11 & 1 & 3 & - & - & - & - & 40 & $2 \%$ \\
\hline Pharmacology & 9 & 23 & - & - & 8 & - & - & - & 40 & $2 \%$ \\
\hline Drug delivery devices/systems/forms & 15 & 8 & 1 & 5 & - & 1 & - & - & 30 & $1 \%$ \\
\hline Allergy & 7 & 7 & 3 & - & - & - & - & - & 17 & $1 \%$ \\
\hline Pregnancy/lactation/teratogenicity/fertility & 14 & 1 & 2 & - & - & - & - & - & 17 & $1 \%$ \\
\hline Drug standars/legal/regulatory & 7 & 4 & 4 & 2 & - & - & - & - & 17 & $1 \%$ \\
\hline Pharmacokinetics & 8 & 2 & 1 & 1 & 4 & & & & 16 & $1 \%$ \\
\hline Nonprescription products & 2 & 4 & 3 & 4 & - & - & - & - & 13 & $1 \%$ \\
\hline Physicochemical properties & 2 & 5 & 6 & - & - & - & - & - & 13 & $1 \%$ \\
\hline Patient information/education & 2 & 4 & 5 & - & - & - & - & - & 11 & $1 \%$ \\
\hline Poisoning/toxicology & 3 & 2 & 2 & - & - & - & - & - & 7 & $<1 \%$ \\
\hline Monitoring parameters & 3 & 1 & & 1 & & & & & 5 & $<1 \%$ \\
\hline Clinical nutrition/metabolic support & 3 & - & 2 & - & - & - & - & - & 5 & $<1 \%$ \\
\hline Contraindications/precautions & 1 & 2 & 1 & - & 1 & - & - & - & 5 & $<1 \%$ \\
\hline Alternative medicine & 1 & - & 1 & - & - & - & - & - & 2 & $<1 \%$ \\
\hline Others* & 5 & 8 & 7 & 1 & - & - & - & - & 21 & $1 \%$ \\
\hline
\end{tabular}

Note that certain queries were under more than one group; *Others included queries related to electronic prescribing system, retrieving drug information from intranet, using intranet to locate drugs, availability of resources, pharmaceutical calculations. No queries received fall under the type biotechnology/gene therapy, investigational products or study design/protocol development/research support 
compatibility. The type of queries varies from centre to centre. For example, drug use and ADRs related queries were most frequent in the studies reported by Joshi et al..$^{[11]}$ and Shadnia et al.$^{[15]}$, whereas interactions and directions for use were the frequent queries in the study by Marvin et al. ${ }^{[16]}$. Even though the type of query varies between studies, most studies ${ }^{[17-19]}$ reported that the bulk of queries concerned patient care.

Requestors felt that telephone was the most convenient and preferred mode of accessing the centre and so most of the queries were received and answered that way. The increasing use of the telephone to provide services directly to consumers is reflected in the growth of hospital based medicine help lines ${ }^{[20]}$. In our study, due to the limited number of clinical pharmacists who provide services in the wards, the proportion of queries during ward rounds were found to be less. This is in contrast to other studies where most queries were received during clinical pharmacy ward rounds ${ }^{[18,21]}$. Very few requestors delivered their queries by visiting the centre. Though no queries were received via e-mail, a small percentage of queries were answered by e-mails. This enabled the requestor to get more information about the query along with the references. In addition, written reply/printed reference literature was given for $0.5 \%$ of queries.

Standard reference text books were the commonly used references (Table 3). The centre commonly utilized World Wide Web sources including licensed drug information websites since it was relatively current, reliable and easy to retrieve drug information for immediate answers. Various medical journals were also used as references for current and comprehensive information.

Few limitations merit mention. This was a retrospective study with the possibility of missing data, documentation errors ${ }^{[22]}$ and retrieval errors that may have skewed data. However the small proportion $(0.25 \%)$ of missing data and the large dataset would have minimized the impact of such errors. Another limitation was the inability to evaluate the quality of the drug information and the opinion of the beneficiaries on the quality of the service provided. Time consumed to answer queries is an important factor ${ }^{[23]}$ that could not be explored in this study.

The drug information centre in a teaching hospital handles a wide range of queries from various healthcare workers, meets specific healthcare needs and serves as a valuable source of drug information. The answers provided are expected to improve patient safety and promote rational use of drugs which are the primary objectives of drug information services. However, the impact of this service on improving patient care and minimizing errors warrants further study. Future studies could focus on the quality of service provided and user satisfaction.

\section{Conflicts of interest:}

There are no conflicts of interest.

\section{Financial support and sponsorship:}

Nil.

\section{TABLE 3: SOME COMMONLY USED RESOURCE MATERIALS IN OUR INSTITUTION}

\begin{tabular}{|c|c|c|}
\hline Web references & Text books used & Journals referred to \\
\hline www.uptodate.com & Martindale: The complete drug reference & British Medical Journal \\
\hline $\begin{array}{l}\text { www.ukmi.nhs.uk/applications/ } \\
\text { fridge/ }\end{array}$ & Stockley's drug interactions & $\begin{array}{l}\text { New England Journal of } \\
\text { Medicine }\end{array}$ \\
\hline www.medicines.org.uk/emc/ & Brigg's "Drugs used in pregnancy and lactation & $\begin{array}{l}\text { The Journal of the American } \\
\text { Medical Association }\end{array}$ \\
\hline www.rxlist.com & Harrison's principles of internal medicine & Pharmacotherapy \\
\hline www.tga.gov.au & British National Formulary & QJM \\
\hline www.medsafe.govt.nz & British National Formulary for Children & Australian Prescriber \\
\hline www.fda.gov & Lexicomp’s “Drug information handbook” & $\begin{array}{c}\text { Journal of Pharmacy Practice } \\
\text { and Research }\end{array}$ \\
\hline www.mhra.gov.uk & Lexicomp's “Geriatric dosage handbook" & Clinical Pharmacist \\
\hline www.cochranelibrary.com & Trissel's stability of compounded formulations & The Pharmaceutical Journal \\
\hline www.ncbi.nlm.nih.gov/pubmed & Adverse drug reactions by Anne Lee & $\begin{array}{c}\text { Indian Journal of Medical } \\
\text { Ethics }\end{array}$ \\
\hline www.scholar.google.co.in & Handbook on injectable drugs & $\begin{array}{l}\text { Journal of Pharmacology and } \\
\text { Pharmacotherapeutics }\end{array}$ \\
\hline www.tripdatabase.com & $\begin{array}{l}\text { Handbook of drug administration via enteral } \\
\text { feeding tubes }\end{array}$ & \\
\hline
\end{tabular}




\section{REFERENCES}

1. Koumis T, Cicero LA, Nathan JP, Rosenberg JM. Directory of pharmacist-operated drug information centers in the United States-2003. Am J Health Syst Pharm 2004;61(19):2033-42.

2. Rosenberg JM, Schilit S, Nathan JP, Zerilli T, McGuire H. Update on the status of 89 drug information centers in the United States. Am J Health-Syst Pharm 2009;66(19):1718-22.

3. Makkonen K. Problems in distribution of scientific knowledge: intrauterine contraceptive devices and drug catalogs. Int J Health Serv 1993;23(1):173-83.

4. Adair RF, Holmgren LR. Do drug samples influence resident prescribing behavior? A randomized trial. Am J Med. 2005;118(8):881-4.

5. Buchkowsky SS, Jewesson PJ. Industry sponsorship and authorship of clinical trials over 20 years. Ann Pharmacother 2004;38(4):579-85.

6. Bond CA, Raehl CL, Franke T. Clinical pharmacy services, pharmacy staffing, and the total cost of care in United States hospitals. Pharmacotherapy 2000;20(6):609-21.

7. Question-ERR - November 2003 [Internet]. [cited 2016 Feb 19]. Available from: http://www.med-errs.com/Question/ Resulterr0311.asp.

8. Seaboldt JA, Kuiper R. Comparison of information obtained from a Usenet newsgroup and from drug information centers. Am J Health Syst Pharm 1997;54:1732-5.

9. Malone P, Kier K, Stanovich J. Drug information: A guide for pharmacists. 4th ed. United States of America: McGraw-Hill; 2012.

10. Puttegowda S, Lakshminarayana S, Ramarathnam N. Assessing the pattern of drug information queries in a rural south Indian tertiary care teaching hospital. Malays J Pharm Sci 2010;8(2):1-9.

11. Joshi MP. University hospital-based drug information service in a developing country. Eur J Clin Pharmacol 1997;53(2):89-94.

12. Tumwikirize AW, Ogwal-Okeng JW, Vernby A, Anokbonggo WW, Gustafsson LL, Lundborg CS. Use of a pilot drug information centre. Afr Health Sci. 2011;11(3):493-8.

13. O'Hare JD, McKee HA, D'Arcy PF. Analysis of drug information queries received by the pharmacy in a large psychiatric hospital. J Clin Hosp Pharm 1984;9(2):139-42.

14. Ali A, Yusoff S, Joffry S, Wahab M. Drug information service awareness program and its impact on characteristics of inquiries at DIS unit in Malaysian public hospital. Arch Pharma Pract 2013;4(1):9-14.

15. Shadnia S, Soltaninejad K, Sohrabi F, Rezvani M, Barari B, Abdollahi M. The Performance of Loghman-Hakim Drug and Poison Information Center from 2006 to 2008. Iran J Pharm Res 2011;10(3):647-52.

16. Marvin V, Park C, Vaughan L, Valentine J. Phone calls to a hospital medicines information helpline: analysis of queries from members of the public and assessment of potential for harm from their medicines. Int $\mathrm{J}$ Pharm Pract 2011;19(2):115-22.

17. Palaian S, Mishra P, Shankar PR, Bista D, Purwar B. Contribution of the regional drug information center towards drug safety. JNMA J Nepal Med Assoc 2006;45(161):216-8.

18. Jimmy B, Jose J, Rao PGM. Short communication: pattern of adverse drug reaction related queries received by the drug information centre of a tertiary care teaching hospital. Pak J Pharm Sci 2007;20(4):333-9.

19. Rajanandh MG, Ruby V, Ramasamy C. Evaluation of drug information services in a tertiary care hospital in kanchipuram district and community pharmacies in neighbouring areas. Indian J Pharm Pract 2011;4(2):51-6.

20. Raynor DK, Sharp JA, Rattenbury H, Towler RJ. Medicine information help lines: a survey of hospital pharmacy-based services in the UK and their conformity with guidelines. Ann Pharmacother 2000;34(1):106-11.

21. Beena G, Padma R. Assessment and evaluation of drug information services provided in a South Indian teaching hospital. Indian J Pharmacol 2005;37(5):315-9.

22. Hartel MJ, Staub LP, Röder C, Eggli S. High incidence of medication documentation errors in a Swiss university hospital due to the handwritten prescription process. BMC Health Serv Res 2011;11:199.

23. Reppe LA, Spigset O, Schjøtt J. Which factors predict the time spent answering queries to a drug information centre? Pharm World Sci 2010;32:799-804. 